\title{
Enhancement of Light Olefins Selectivity Over N-Doped Fischer-Tropsch Synthesis Catalyst Supported on Activated Carbon Pretreated with $\mathrm{KMnO}_{4}$
}

\author{
Zhipeng Tian ${ }^{1,2}{ }^{\mathbb{D}}$, Chenguang Wang ${ }^{1, *}, \mathrm{Zhan} \mathrm{Si}^{1}{ }^{1}$, Chengyan Wen ${ }^{1} \mathbb{D}, \mathrm{Ying}_{\mathrm{Xu}}{ }^{1}$, Wei Lv ${ }^{1}$, \\ Lungang Chen ${ }^{1}$, Xinghua Zhang ${ }^{1}$ and Longlong $\mathrm{Ma}^{1}$ \\ 1 CAS Key Laboratory of Renewable Energy, Guangdong Provincial Key Laboratory of New and Renewable \\ Energy Research and Development, Guangzhou Institute of Energy Conversion, Chinese Academy \\ of Sciences, Guangzhou 510640, China; tianzp@ms.giec.ac.cn (Z.T.); sizhan43@126.com (Z.S.); \\ wency1@ms.giec.ac.cn (C.W.); xuying@ms.giec.ac.cn (Y.X.); lvwei@ms.giec.ac.cn (W.L.); \\ chenlg1981@ms.giec.ac.cn (L.C.); zhangxh@ms.giec.ac.cn (X.Z.); mall@ms.giec.ac.cn (L.M.) \\ 2 University of Chinese Academy of Sciences, Beijing 100049, China \\ * Correspondence: wangcg@ms.giec.ac.cn; Tel.: +86-20-37029721
}

Received: 11 May 2019; Accepted: 29 May 2019; Published: 31 May 2019

check for updates

\begin{abstract}
Ammonium iron citrate was used as an iron precursor in order to prepare N-doped catalysts supported on $\mathrm{KMnO}_{4}$ pretreated activated carbon (10MnK-AC). Iron nitride was synthesized in company with the formation of $\alpha-\mathrm{Fe}_{2} \mathrm{O}_{3}$ on $10 \mathrm{MnK}-\mathrm{AC}$. The characterizations of the catalysts show that nitrogen atoms were doped into iron lattice rather than the networks of the carbon support. The performance of Fischer-Tropsch synthesis to light olefins (FTO) suggest an improvement in O/P ratio (olefins to paraffins molar ratio of $\mathrm{C}_{2}-\mathrm{C}_{4}$ ) over the iron catalysts supported on $10 \mathrm{MnK}-\mathrm{AC}$. The further promotion of light olefins selectivity (up to 44.7\%) was obtained over FeN-10MnK-AC catalyst owing to the collaborative contribution of the electron donor effect of nitrogen and the suppression effect on the second hydrogenation over 10MnK-AC support.
\end{abstract}

Keywords: nitrogen-doping; iron nitrides; light olefins; $\mathrm{CO}$ hydrogenation; $\mathrm{KMnO}_{4}$ pretreatment

\section{Introduction}

Fischer-Tropsch synthesis to light olefins (FTO) from syngas derived from coal, natural gas and biomass is a typical approach to obtain the building blocks for chemical industry [1]. Especially, the production of fungible fuels from CO-rich syngas derived from biomass is a promising way for the sustainable development of the world energy economy. Light olefins obtained from the FTO reaction can further be oligomerized to gasoline and diesel fuels, which is more controllable than a one-step FTS reaction [2]. High isomerization to iso-paraffins during the olefin oligomerization contributes to the high-octane rate of gasoline [3]. Iron-based supported catalysts have been widely studied because of their low cost, better selectivity towards light alkenes and proper water-gas shift (WGS) reaction activity for CO-rich syngas [4-6]. FTO catalytic performance is highly related to the catalyst properties such as active phases generated during the reduction and reaction processes [7-9], promoters [10,11] and the interactions with support for supported iron catalysts. The theory that iron carbide is the active phase in Fischer-Tropsch synthesis is widely accepted [12]. However, catalyst sintering and carbon deposition on active phase lead to a relatively poor catalyst stability for iron-based catalysts at such severe reaction conditions $[13,14]$. In order to extend the lifetime of catalyst, a novel iron catalyst supported on $\mathrm{KMnO}_{4}$ pretreated activated carbon (AC) has been prepared in our previous 
work [15].The better stability of iron particles and higher light olefins selectivity is obtained due to the promotion of potassium and manganese retained on the AC surface. The existence of a manganese promoter also inhibits the dissociation of hydrogen which makes the hydrogenation of the $\mathrm{C}^{*}$ intermediate less active. The competitive adsorption of hydrogen on manganese oxides retards the further hydrogenation of unsaturated hydrocarbons and enhances light olefins selectivity. Meanwhile, as the structure promoter, the bonding force between iron species and $\mathrm{MnO}_{\mathrm{x}}$ improves dispersity and stability of active sites. Alkali promoters such as $\mathrm{Na}, \mathrm{K}$, etc. can facilitate the formation of iron carbides, and it reduces the production of methane. Recently, the introduction of nitrogen atoms into iron-based supported catalysts for Fischer-Tropsch synthesis have been applied to increase the selectivity of lower olefins [16-20]. It is found that doping nitrogen atoms into the matrix of carbon materials can change the electronic environment and increase FTO performances. $\mathrm{N}$ atoms acted as the electron donor suppresses second hydrogenation and improves light olefins selectivity. In contrast, Bao's group [21] has investigated the enhancement of iron nitrides supported on carbon nanotube (CNT) walls catalysts. They synthesized a series of FeN/CNT catalysts by heating conventional Fe/CNT catalysts at $450{ }^{\circ} \mathrm{C}$ in ammonia stream and found that iron nitride $\left(\mathrm{Fe}_{2} \mathrm{~N}\right)$ exhibits higher activity and $\mathrm{C}_{2}-\mathrm{C}_{4}$ alkenes selectivity than iron carbides, which also verifies the proposition suggested by Anderson et al [22]. Moreover, the effects of Mn and K added to FeN/CNT catalyst that prohibit second hydrogenation and facilitate $\mathrm{CO}$ adsorption are discussed [23].

Following these previous studies, herein we have prepared an $\mathrm{N}$-doped iron catalyst supported on $\mathrm{KMnO}_{4}$ pretreated AC and compared its FTO performance with an N-doped catalyst supported on AC and other catalysts in our previous studies [15]. Unlike the heating treatment in ammonia stream [21], we have introduced $\mathrm{N}$ atoms into the Fe lattice by using ammonium iron citrate as a precursor. A series of catalyst characterizations were conducted and ascertained the position of nitrogen atoms in catalysts. The synergistic effect between N-doped active phase and MnK-AC support was discussed as well by associating characterization with FTO reaction results.

\section{Results and Discussion}

As is shown in Figure 1, the morphology of the catalysts with different supports (AC and $\mathrm{KMnO}_{4}$-treated $\mathrm{AC}$ ) and iron precursors (iron nitrate and ammonium iron citrate) were determined by Powder X-ray diffraction (XRD) analysis. Obviously, all these catalysts showed typical peaks at $26.5^{\circ}$ and $44.6^{\circ}$, which can be attributed to graphitic carbon. Further, the intensity of the broad peak around $25^{\circ}$ can be attributed to the amorphous carbon in AC. The relative ratio of amorphous carbon and graphitic carbon can be determined by $\mathrm{I}_{\mathrm{D}} / \mathrm{I}_{\mathrm{G}}$ ratio in Raman spectra (Table 1 ). The $\mathrm{I}_{\mathrm{D}} / \mathrm{I}_{\mathrm{G}}$ ratio was determined by the peak intensity of D band $\left(1350 \mathrm{~cm}^{-1}\right)$ and $\mathrm{G}$ band $\left(1575 \mathrm{~cm}^{-1}\right)$ in Raman spectra. The $\mathrm{D}$ band means the disorder in carbon materials and the $\mathrm{G}$ band means the graphitization degree of carbon materials. The $\mathrm{I}_{\mathrm{D}} / \mathrm{I}_{\mathrm{G}}$ ratios of Fe-10MnK-AC and FeN-10MnK-AC are lower than those of $\mathrm{Fe}-\mathrm{AC}$ and $\mathrm{FeN}-\mathrm{AC}$ catalysts. It implies that $\mathrm{KMnO}_{4}$ pretreatment on the AC support increases its graphitization degree. On the other hand, no obvious changes in $\mathrm{I}_{\mathrm{D}} / \mathrm{I}_{\mathrm{G}}$ ratio are observed by comparing the results of Fe- catalysts and N-doped FeN- catalysts. That is to say, nitrogen doping has no effect on the properties of carbon support. This result is opposite to the common sense that nitrogen introduction in carbon material decreases its graphitization degree and improves the defectiveness [24,25]. Probably, $\mathrm{N}$ atoms attached to the metal oxides rather than carbon support. Table 1 also offers the metal element contents of $\mathrm{Fe}, \mathrm{Mn}$ and $\mathrm{K}$ analyzed by inductive coupled plasma-atomic emission spectroscopy (ICP-AES), which are almost the same with the desired loadings within the preparation error. The pore properties are provided in Table 1 as well. From the specific surface area and pore size, no difference between undoped and N-doped catalysts. However, there is a large decrease of specific area and a growth of pore size compared to the untreated catalysts to $\mathrm{KMnO}_{4}$-pretreated catalysts. This is due to the high content of manganese and the relative low content of porous $\mathrm{AC}$ on $\mathrm{KMnO}_{4}$-pretreated catalysts (Fe-10MnK-AC and FeN-10MnK-AC). This results in the decline in adsorption ability of reactants, which further reduces the reactivity. 


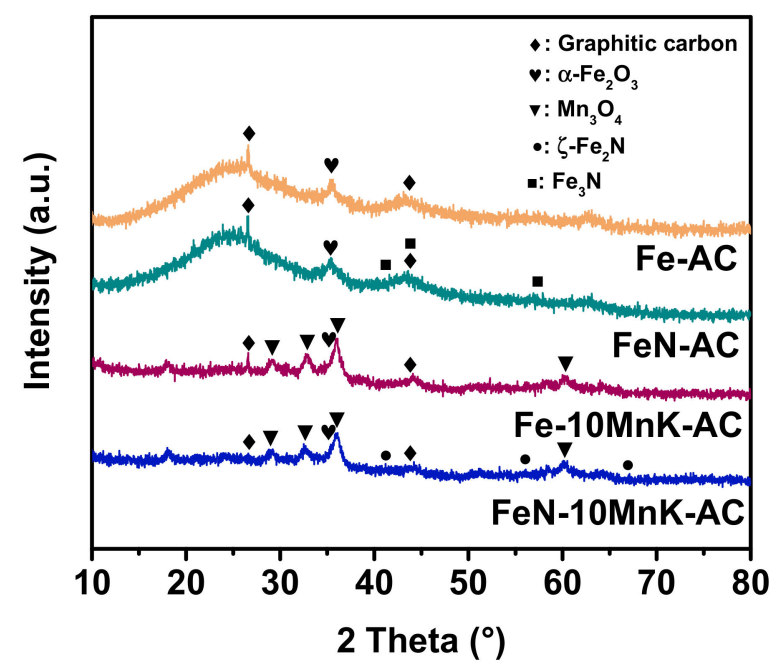

Figure 1. XRD patterns of catalysts: Fe-AC, FeN-AC, Fe-10MnK-AC and FeN-10MnK-AC. Graphitic carbon ( $\bullet$ JCPDS No. 75-2078), $\alpha-\mathrm{Fe}_{2} \mathrm{O}_{3}$ ( $\bullet$, JCPDS No. 73-0603), $\mathrm{Mn}_{3} \mathrm{O}_{4}$ ( $\mathbf{v}, \mathrm{JCPDS}$ No. 75-1560), $\varepsilon-\mathrm{Fe}_{3} \mathrm{~N}\left(\boldsymbol{\bullet}, \mathrm{JCPDS}\right.$ No. 83-0876) and $\zeta-\mathrm{Fe}_{2} \mathrm{~N}(\bullet$, JCPDS No. 50-0958) are marked in the patterns.

Table 1. Elemental contents and properties of supported catalysts.

\begin{tabular}{|c|c|c|c|c|c|c|c|c|}
\hline \multirow{2}{*}{ Catalysts } & \multicolumn{3}{|c|}{$\begin{array}{c}\text { Element Contents } \\
(w t \%)^{1}\end{array}$} & \multirow{2}{*}{$\begin{array}{l}\mathrm{N} \text { atom. } \\
(\%)^{2}\end{array}$} & \multirow{2}{*}{$\mathrm{I}_{\mathrm{D}} / \mathrm{I}_{\mathrm{G}}{ }^{3}$} & \multirow{2}{*}{$\begin{array}{c}\text { Iron Average } \\
\text { Particle Size (nm) }\end{array}$} & \multirow{2}{*}{$\begin{array}{c}\text { Surface } \\
\text { Area }\left(\mathrm{m}^{2} / \mathrm{g}\right)\end{array}$} & \multirow{2}{*}{$\begin{array}{l}\text { Pore Size } \\
\quad(\mathrm{nm})\end{array}$} \\
\hline & $\mathrm{Fe}$ & Mn & $\mathbf{K}$ & & & & & \\
\hline Fe-AC & 10.1 & - & - & 0.4 & 1.42 & $3.2 \pm 1.0$ & 575.3 & 2.58 \\
\hline FeN-AC & 9.7 & - & - & 1.6 & 1.45 & $5.4 \pm 1.4$ & 549.3 & 2.56 \\
\hline Fe-10MnK-AC & 10.1 & 29.3 & 5.3 & 0.4 & 1.34 & $2.0 \pm 0.9$ & 190.6 & 3.34 \\
\hline FeN-10MnK-AC & 9.4 & 26.7 & 4.6 & 2.1 & 1.35 & $4.2 \pm 1.5$ & 187.1 & 3.37 \\
\hline
\end{tabular}

${ }^{1}$ Determined by ICP-AES. ${ }^{2}$ Calculated by X-ray photoelectron spectroscopy (XPS) spectra. ${ }^{3}$ Calculated by the peak intensity of D band $\left(1350 \mathrm{~cm}^{-1}\right)$ and $\mathrm{G}$ band $\left(1575 \mathrm{~cm}^{-1}\right)$ in Raman spectra.

As reported by our previous work [15], the major peak at $35.6^{\circ}$ can be assigned to the (110) crystal plane of $\alpha-\mathrm{Fe}_{2} \mathrm{O}_{3}$ (JCPDS No. 73-0603). And three characteristic peaks at $28.9^{\circ}, 32.4^{\circ}$ and $36.1^{\circ} \mathrm{can}$ be ascribed to $\mathrm{Mn}_{3} \mathrm{O}_{4}$ (JCPDS No. 75-1560). This implies that different supports and precursors have no significant effect on the crystal structure of iron oxides on catalysts. Interestingly, two tiny peaks emerged at $40.8^{\circ}$ and $57.0^{\circ}$ in the XRD spectrum of FeN-AC can be attributed to iron nitride $\varepsilon-\mathrm{Fe}_{3} \mathrm{~N}$ (JCPDS No. 83-0876). Compared with the result of Fe-AC, it is believed that part of iron oxide transformed into iron nitride during calcination by using ammonium iron citrate as precursor. In this procedure, ammonium iron citrate was decomposed and the volatilized $\mathrm{NH}_{3}$ replaced oxygen atoms in iron oxide by nitridation process. Then the formation of iron nitride is preceded through the incorporation of nitrogen into the iron lattice [22]. Specially, based on the XRD spectrum analysis result, another type of iron nitride ( $\zeta-\mathrm{Fe}_{2} \mathrm{~N}$, JCPDS No. 50-0958) is acquired on FeN-10MnK-AC catalyst. The difference of iron nitride crystal phase is probably ascribed to the existence of manganese oxides on the surface of carbon support. The presence of $\mathrm{Mn}$ facilitates the formation of $\zeta-\mathrm{Fe}_{2} \mathrm{~N}$ phase according to previous studies [23]. Only a small fraction of iron nitrides was obtained on FeN-AC and FeN-10MnK-AC catalysts according to the lower intensity of the peaks attributed to $\varepsilon-\mathrm{Fe}_{3} \mathrm{~N}$ and $\zeta-\mathrm{Fe}_{2} \mathrm{~N}$. In order to give a detailed analysis of the nitrogen atoms and the interaction with iron, XPS analysis was conducted. As is illustrated in the XPS survey spectra (Figure 2a), both FeN-AC and FeN-10MnK-AC show a relatively weak N1s photoelectron peak at $400.0 \mathrm{eV}$, which are revealed more specifically in high resolution spectra of the N1s region (Figure 2b). The nitrogen content of each catalyst is calculated and determined by the relative peak area of the XPS survey spectra, which are $0.4 \%$ (Fe-AC), $1.6 \%$ (FeN-AC), $0.4 \%$ (Fe-10MnK-AC) and $2.1 \%$ (FeN-10MnK-AC), respectively. However, the $\mathrm{N}$ content is too low so that the N1s peaks are hard to deconvolute. On the basis of the 
Fe2p spectra shift to higher binding energies (Figure 2c), it can be inferred that the interaction between $\mathrm{Fe}$ and $\mathrm{N}$ is formed on the catalysts when using ammonium iron citrate as precursor. It means that in the crystal lattice of iron oxides, $\mathrm{N}$ atoms partially replace $\mathrm{O}$ atoms and get into the Fe lattice to form iron nitrides [26,27]. In brief, nitrogen atoms are not doped into carbon networks but iron lattice. Additionally, from the results of transmission electron microscopy (TEM) images and corresponding energy dispersive spectroscopy (EDS) mapping of FeN-10MnK-AC (Figure 3), we can easily find out that $\mathrm{Fe}, \mathrm{Mn}, \mathrm{K}$ and $\mathrm{N}$ dispersed on the carbon substrate homogeneously. The particle size distribution of FeN-10MnK-AC catalyst is presented as well. The average particle size is $4.2 \pm 1.5 \mathrm{~nm}$, which is larger than that of Fe-10MnK-AC catalyst $(2.0 \pm 0.9 \mathrm{~nm})$. The average particle size of Fe-AC and FeN-AC are $3.2 \pm 1.0 \mathrm{~nm}$ and $5.4 \pm 1.4 \mathrm{~nm}$ separately. It shows a similar trend with those catalysts supported on $\mathrm{KMnO}_{4}$ pretreated AC. Using ammonium iron citrate as iron precursor leads to the increase of iron particle size. The effective contact area decreases and leads to the reduction of catalyst activity, which can be observed in the FTO performances (Table 2).
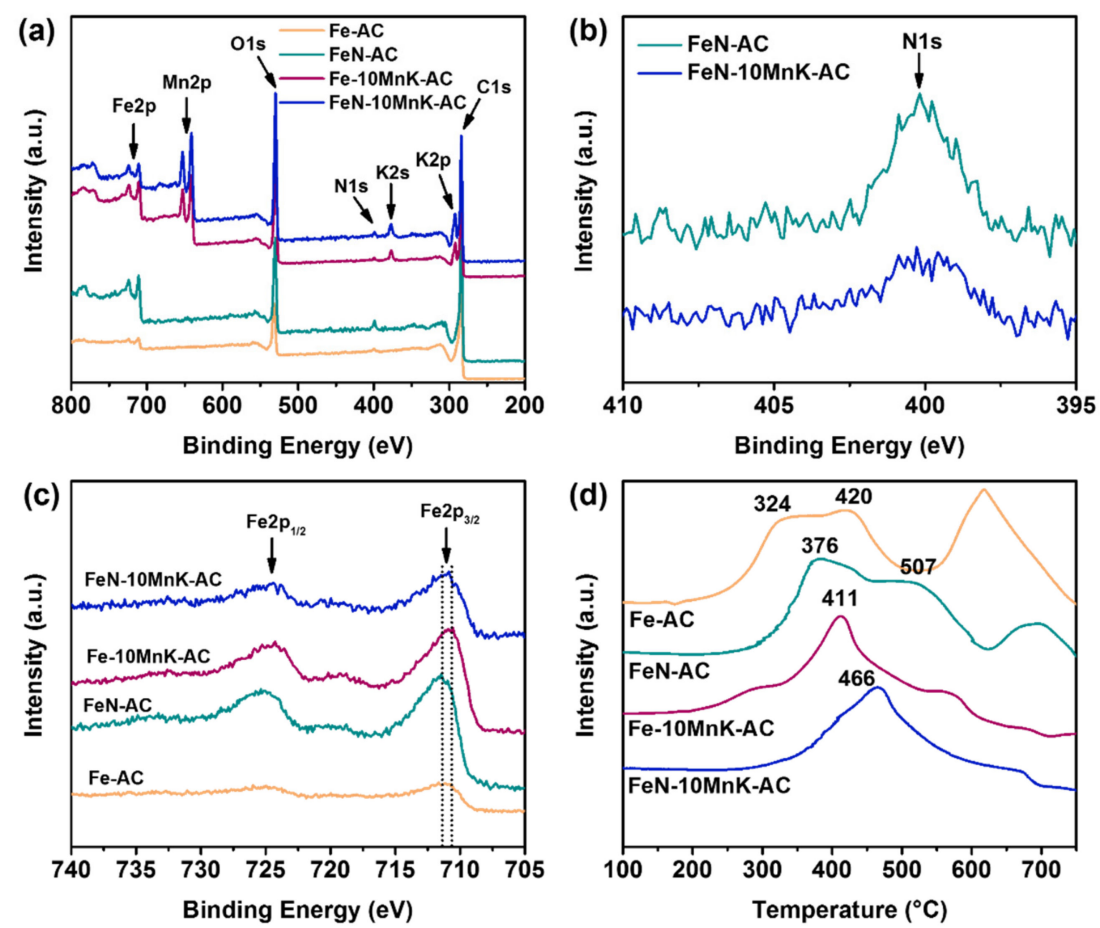

Figure 2. (a) XPS survey spectra of the Fe-AC, FeN-AC, Fe-10MnK-AC and FeN-10MnK-AC catalysts. The sharp photoelectron peaks at $712.1 \mathrm{eV}(\mathrm{Fe} 2 \mathrm{p}), 642.2 \mathrm{eV}(\mathrm{Mn} 2 \mathrm{p}), 531.1 \mathrm{eV}(\mathrm{O} 1 \mathrm{~s}), 378.0 \mathrm{eV}(\mathrm{K} 2 \mathrm{~s})$, $294.1 \mathrm{eV}(\mathrm{K} 2 \mathrm{p}), 285.0 \mathrm{eV}(\mathrm{C} 1 \mathrm{~s})$ and a weak photoelectron peak at $400.0 \mathrm{eV}(\mathrm{N} 1 \mathrm{~s})$ are marked in the spectra. (b) High resolution XPS spectra of the N1s region for FeN-AC and FeN-10MnK-AC catalysts. (c) Fe2p XPS spectra and (d) hydrogen temperature programmed reduction $\left(\mathrm{H}_{2}-\mathrm{TPR}\right)$ profiles of Fe-AC, FeN-AC, Fe-10MnK-AC and FeN-10MnK-AC catalysts. 

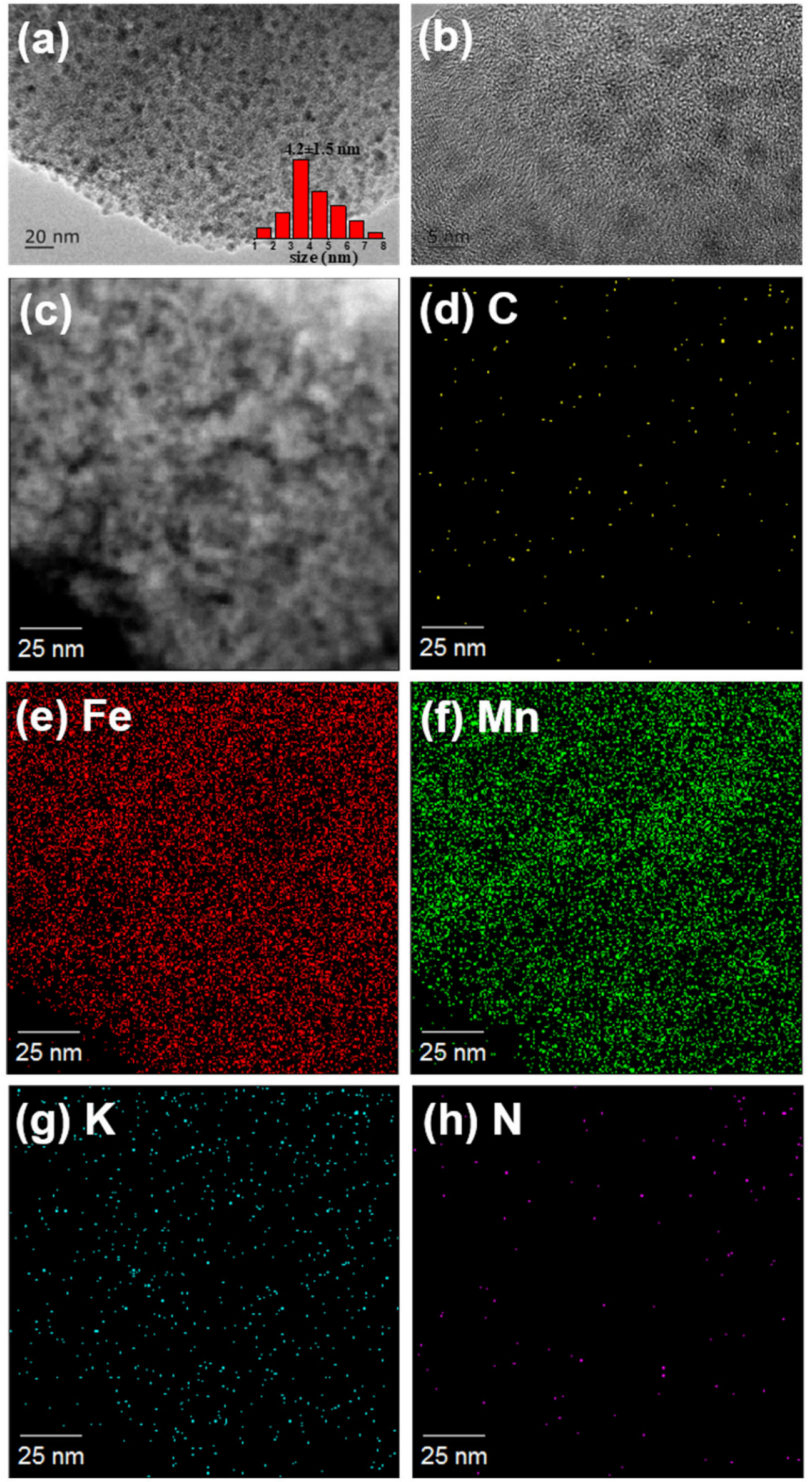

Figure 3. (a) TEM and (b) high resolution TEM (HRTEM) images of FeN-10MnK-AC catalysts. (c) High-angle annular dark field scanning transmission electron microscopy (HAADF-STEM) image and corresponding elemental mapping of FeN-10MnK-AC catalysts: (d) C; (e) Fe; (f) Mn; (g) K; (h) N.

Table 2. FTO performances of iron catalysts and N-doped iron catalysts.

\begin{tabular}{|c|c|c|c|c|}
\hline Catalysts & Fe-AC & FeN-AC & Fe-10MnK-AC & FeN-10MnK-AC \\
\hline GHSV $\left(h^{-1}\right)$ & 15,000 & 15,000 & 15,000 & 15,000 \\
\hline CO conversion $(\%)$ & 64.8 & 59.7 & 51.0 & 38.5 \\
\hline $\mathrm{H}_{2}$ conversion $(\%)$ & 60.6 & 57.4 & 29.5 & 17.1 \\
\hline $\mathrm{H}_{2} / \mathrm{CO}$ usage & 0.97 & 1.00 & 0.55 & 0.46 \\
\hline $\mathrm{CO}_{2}$ selectivity $(\% \mathrm{C})$ & 61.7 & 46.0 & 60.7 & 47.2 \\
\hline FTY $^{1}\left(\mathrm{~mol}_{\mathrm{co}} \cdot \mathrm{g}_{\mathrm{Fe}}{ }^{-1} \cdot \mathrm{h}^{-1}\right)$ & 1.77 & 1.66 & 1.48 & 1.12 \\
\hline \multicolumn{5}{|l|}{ Product selectivity (wt \%) } \\
\hline $\mathrm{CH}_{4}$ & 28.9 & 27.5 & 21.1 & 22.5 \\
\hline$C_{2}=-C_{4}=$ & 31.2 & 30.8 & 30.1 & 44.7 \\
\hline $\mathrm{C}_{2}{ }^{0}-\mathrm{C}_{4}{ }^{0}$ & 23.4 & 23.7 & 11.9 & 8.9 \\
\hline $\mathrm{C}_{5+}$ & 16.5 & 18.1 & 36.9 & 23.9 \\
\hline $\mathrm{O} / \mathrm{P}^{2}$ & 1.2 & 1.1 & 2.5 & 5.0 \\
\hline
\end{tabular}

1 FTY is the Fe time yield which is calculated as the mole number of $\mathrm{CO}$ molecules converted per gram of iron per hour. ${ }^{2} \mathrm{O} / \mathrm{P}$ is the ratio of olefins to paraffins calculated by molar fraction of $\mathrm{C}_{2}-\mathrm{C}_{4}$ hydrocarbons. 
The reduction performances of these prepared catalysts were analyzed by a temperature programmed reduction measurement in hydrogen $\left(\mathrm{H}_{2}-\mathrm{TPR}\right)$. This is highly related to the intension of metal-support and metal-metal interactions. As to the comparison of Fe-AC and FeN-AC catalysts, $\mathrm{N}$-doped iron catalysts show a stronger interaction that retards the reduction procedure and promotes the reduction peaks (from $324{ }^{\circ} \mathrm{C}$ to $376{ }^{\circ} \mathrm{C}$ and $420{ }^{\circ} \mathrm{C}$ to $507{ }^{\circ} \mathrm{C}$ ), which are attributed to the $\mathrm{Fe}_{2} \mathrm{O}_{3} \rightarrow \mathrm{Fe}_{3} \mathrm{O}_{4}$ and $\mathrm{Fe}_{3} \mathrm{O}_{4} \rightarrow \mathrm{FeO}$ transformation stages. The mixed spinel oxides ( $\mathrm{Fe}, \mathrm{Mn}$ ) $\mathrm{O}_{\mathrm{x}}$ with strong interaction leads to broad reduction peaks of Fe-10MnK-AC and FeN-10MnK-AC catalysts, which impedes the reduction of iron oxide to some extent. Similarly, the $\mathrm{H}_{2}$-TPR profiles of Fe-10MnK-AC and FeN-10MnK-AC catalysts show an increase in reduction peaks (from $411^{\circ} \mathrm{C}$ to $466^{\circ} \mathrm{C}$ ). The improvement between traditional iron catalysts and $\mathrm{N}$-doped catalysts means that the existence of slight amount of $\mathrm{N}$ in the lattice of iron oxide or Fe-Mn mixed oxides inhibits the reducibility of supported catalysts. On the other hand, a considerable difference in catalyst reducibility also proves the interaction between doped nitrogen and metal promoters ( $\mathrm{Mn}$ and $\mathrm{K}$ ).

The intrinsic effects of the $\mathrm{KMnO}_{4}$ pretreatment on carbon support, nitrogen doping, and their collaboration could be investigated by associating FTO performances and catalysts properties. Herein, the catalytic performances of the iron catalysts as well as $\mathrm{N}$-doped iron catalysts that loaded on $\mathrm{AC}$ and $\mathrm{KMnO}_{4}$ pretreated AC have been analyzed and compared. As presented in Table 2, the absorption and activation degree of $\mathrm{CO}$ and $\mathrm{H}_{2}$ on the active sites of the catalysts were presented as $\mathrm{CO}$ conversion, $\mathrm{H}_{2}$ conversion and the effective utilization of these two kinds of feed gas, which is denoted as the $\mathrm{H}_{2} / \mathrm{CO}$ usage ratio. $\mathrm{CO}$ conversions of the iron catalysts supported on $\mathrm{KMnO}_{4}$ pretreated $\mathrm{AC}$ (Fe-10MnK-AC and FeN-10MnK-AC) decreased compared with iron catalysts supported on AC, which is probably caused by the metal-support interaction between iron and manganese that retards the $\mathrm{CO}$ dissociation. $\mathrm{H}_{2}$-TPR results show that the iron oxides supported on $10 \mathrm{MnK}-\mathrm{AC}$ are difficult to reduce, which also verifies the less active catalytic surface. In addition, $\mathrm{H}_{2} / \mathrm{CO}$ usage dramatically reduced from 1 to about 0.5 . When $\mathrm{H}_{2} / \mathrm{CO}$ usage ratio decreases, the chemisorption and dissociation of $\mathrm{H}_{2}$ is relatively lower than that of $\mathrm{CO}$. And the hydrogenation activity on the active sites is reduced. Considering the catalyst properties, it implies that manganese existed on pretreated AC hinders the dissociation rate of hydrogen. It effectively suppresses second hydrogenation of alkenes and the formation of $\mathrm{CH}_{4}$ [28]. As shown in the hydrocarbon distributions of these catalysts, selectivity of methane decreased from $28.9 \%$ (Fe-AC) and $27.5 \%$ (FeN-AC) to $21.1 \%$ (Fe-10MnK-AC) and 22.5\% (FeN-10MnK-AC). Besides, the $\mathrm{O} / \mathrm{P}$ ratio also exhibits a promotion owing to the addition of manganese and potassium in the pretreatment process of support with $\mathrm{KMnO}_{4}$ solution. These catalysts supported on 10MnK-AC suppressed $\mathrm{H}_{2}$ adsorption and dissociation on active sites [29]. From the hydrogenation distribution, it can be concluded that these catalysts (Fe-10MnK-AC and FeN-10MnK-AC) have higher $\mathrm{C}_{5+}$ selectivities. This is regarded as a decrease of hydrogenation activity which leads to the higher amount of unsaturated intermediates, and this causes the increase of carbon chain growth ability.

According to the XRD and XPS results, a slight amount of nitrogen was introduced through the decomposition of ammonium iron citrate during calcination procedure. Unlike previous studies [17-19], nitrogen atoms were originated from the iron precursor with $\mathrm{NH}_{4}{ }^{+}$group rather than exogenous $\mathrm{NH}_{3}$ source, which leads to a more affiliative contact with iron. This is associated with the XRD results that iron nitrides were formed along with the formation of iron oxide. No evident changes of $I_{D} / I_{G}$ ratio on Raman spectra between iron catalysts and catalysts doping with nitrogen is observed. It implies that the introduction of nitrogen atoms has no effects on the properties of carbon support and nitrogen atoms existed in the crystal lattice of iron oxide. Compared with Fe-AC, FeN-AC have nearly no shift on hydrocarbon distribution and the ratio of olefins to paraffins $(\mathrm{O} / \mathrm{P})$. Only a decrease of $\mathrm{CO}_{2}$ selectivity from $61.7 \%$ to $46.0 \%$ was observed. Fe-10MnK-AC and FeN-10MnK-AC exhibits a similar trend on $\mathrm{CO}_{2}$ selectivity as well. It signifies that nitrogen doping weakens WGS reaction activity, which favors the effective yield of desired hydrocarbons. Furthermore, an enormous shift to $C_{2}-C_{4}$ hydrocarbons selectivity is detected by comparing Fe-10MnK-AC and FeN-10MnK-AC catalysts. This is especially the case insofar as up to $44.7 \%$ of light olefins selectivity is obtained over FeN-10MnK-AC, 
which is higher than those over Fe-AC (31.2\%), FeN-AC (30.8\%) and Fe-10MnK-AC (30.1\%) catalysts. The generation of $\mathrm{C}_{2}-\mathrm{C}_{4}$ alkanes is further retarded owing to the combined effect of promoter $\mathrm{Mn}$ and $\mathrm{K}$ as well as the doping agent $\mathrm{N}$. The $\mathrm{O} / \mathrm{P}$ ratio is improved at the same time. Nitrogen doping in Fe-Mn mixed oxides further enhances the catalyst surface basicity since it plays a role of electron donor and weakens $\mathrm{H}_{2}$ dissociation during reaction, which is also the underlying reason why a lower $\mathrm{H}_{2} / \mathrm{CO}$ usage ratio is achieved on FeN-10MnK-AC than Fe-10MnK-AC [30]. More explicitly, the introduced nitrogen atoms modifies the electron environment around the active sites. Electron pairs of nitrogen atoms occupy the electron hole pairs of adsorbed $\mathrm{H}^{+}$ions. This retards the formation of $\mathrm{C}-\mathrm{H}$ bond and ulteriorly limits the second hydrogenation of unsaturated hydrocarbons adsorbed on active sites. As is described in catalyst characterization, $\zeta-\mathrm{Fe}_{2} \mathrm{~N}$ with an orthorhombic structure is formed on FeN-10MnK-AC with the help of manganese while $\varepsilon-\mathrm{Fe}_{3} \mathrm{~N}$ is formed on FeN-AC. During the reaction, the dissociative $\mathrm{CO}$ diffuses into the lattice of iron nitrides and the iron carbonitrides phase is generated. It is regarded as a more stable active phase under FTO reaction conditions [21]. From the comparison of FTO performances, a synergistic effect of $\zeta-\mathrm{Fe}_{2} \mathrm{~N}$ and the promoters $\mathrm{Mn}$ and $K$ serve as a vital role in impeding the excessive hydrogenation of intermediate $C^{*}$ attached to FTO active sites. The competitive adsorption to hydrogen of manganese and the electron donation effect of nitrogen increase the FTO performances on FeN-10MnK-AC catalyst.

\section{Materials and Methods}

Catalysts used in this work were prepared by a facile method with some modifications reported by our group [15]. Briefly, the powdered wooden activated carbon (200 mesh, $\sim 1400 \mathrm{~m}^{2} / \mathrm{g}$, pore volume: $0.67 \mathrm{~mL} / \mathrm{g}$, purity: $\geq 98 \%$, purchased form Sunson Activated Carbon Technology CO., Ltd., Shanghai, China) was firstly pretreated by boiling water to remove ash. And then, washed-out AC was redispersed in $10 \mathrm{wt} \% \mathrm{HNO}_{3}$ aqueous solution and refluxed at $80^{\circ} \mathrm{C}$ for $5 \mathrm{~h}$ in order to remove residual metal ions and improve oxygen-containing groups on the surface of $\mathrm{AC}$ to enhance iron particle dispersity during impregnation and calcination process. The as-treated $\mathrm{AC}$ was filtered and washed until $\mathrm{pH}=7$ and dried overnight.

The dried AC was treated by $\mathrm{KMnO}_{4}$ aqueous solution. Namely, $3 \mathrm{~g}$ AC was dispersed in $200 \mathrm{~mL}$ $0.1 \mathrm{~mol} / \mathrm{L} \mathrm{KMnO}_{4}$ aqueous solution and placed in a water bath at $70{ }^{\circ} \mathrm{C}$ for $30 \mathrm{~min}$ with magnetic stirring. After washing with deionized water for several times, the obtained AC was dried overnight at $120^{\circ} \mathrm{C}$ and denoted as $10 \mathrm{MnK}-\mathrm{AC}$.

$\mathrm{Fe}-\mathrm{AC}$ and Fe-10MnK-AC catalysts were prepared by incipient wetness impregnation method. Pretreated $\mathrm{AC}$ and $10 \mathrm{MnK}-\mathrm{AC}$ were separately impregnated with $\mathrm{Fe}\left(\mathrm{NO}_{3}\right)_{3} \cdot 9 \mathrm{H}_{2} \mathrm{O}$ solution (nominal Fe loading: $10 \mathrm{wt} \%$ ). The suspensions were subject to magnetic stirring at room temperature for $24 \mathrm{~h}$ in order to evaporate the solvent and then dried at $120^{\circ} \mathrm{C}$ for $12 \mathrm{~h}$. Finally, samples were calcined under static $\mathrm{N}_{2}$ at $300{ }^{\circ} \mathrm{C}$ for $3 \mathrm{~h}$ (heating rate: $2{ }^{\circ} \mathrm{C} / \mathrm{min}$ ) and Fe-AC and Fe-10MnK-AC catalysts were received. In contrast, FeN-AC and FeN-10MnK-AC were prepared with the same method except that the iron precursor was replaced with ammonium ferric (III) citrate, which is also regarded as the source of nitrogen that comes from the decomposition of $\mathrm{NH}_{4}{ }^{+}$[31-33].

The morphologies of the catalysts were observed by a TEM (JEOL-2100F, Tokyo, Japan) at $200 \mathrm{kV}$ accelerating voltage and the elemental mappings of the catalysts were obtained by EDS attached to TEM. $\mathrm{N}_{2}$ adsorption-desorption analysis was carried out at $77 \mathrm{~K}$ to obtain pore properties such as specific surface area, total pore volume and pore size distribution on Micromeritics ASAP2460, Norcross, GA, USA. Powder X-ray diffraction (XRD) patterns by X-ray diffraction radiation (X'pert Pro MPD with $\mathrm{Cu} \mathrm{K} \alpha(\lambda=0.154 \mathrm{~nm})$ radiation, $2 \theta=5-80^{\circ}$, Philips, Almelo, Netherland) was used to measure the phase and structure of the catalysts we prepared. XPS spectra were conducted using a Thermo ESCALAB 250XI, USA. The metal contents were determined by inductive coupled plasma-atomic emission spectroscopy (ICP-AES, OPTIMA 8000DV, PerkinElmer, Waltham, MA, USA). Raman spectra were measured on a Raman microscope (LabRAM HR800-LS55, HORIBA, Paris, France) using $532 \mathrm{~nm}$ laser excitation at ambient temperature. $\mathrm{H}_{2}$-TPR was conducted in a U-shape quartz tube reactor with 
a thermal conductivity detector (TCD) with a $\mathrm{H}_{2}$ flow rate of $50 \mathrm{ml} / \mathrm{min}$ by Quantachrome CPB-1, Boynton Beach, FL, USA.

The Fischer-Tropsch synthesis performance of the catalysts we prepared were conducted in a fixed bed reactor system. The reactor's inner diameter is $5 \mathrm{~mm}$ and the length is $250 \mathrm{~mm}$. For every reaction experiment, $0.2 \mathrm{~g}$ catalyst was firstly diluted with $0.8 \mathrm{~g}$ quartz sand (60-80 mesh) homogeneously and sealed in the center of the reactor with quartz wool. Then, catalyst was reduced on site by syngas (a $\mathrm{H}_{2} / \mathrm{CO} / \mathrm{N}_{2}$ ratio of $47.5 / 47.5 / 5$ by volume and $\mathrm{N}_{2}$ was used as the internal standard) at $350^{\circ} \mathrm{C}$ and ambient pressure for $12 \mathrm{~h}$ and FT synthesis reaction was conducted under the same syngas at $320^{\circ} \mathrm{C}$, $2 \mathrm{MPa}$. And the gas hourly space velocity (GHSV) was set to $15,000 \mathrm{~h}^{-1}$ by regulating the gas flow rate. An online gas chromatography (GC7890B, Agilent, Santa Clara, CA, USA) equipped with an flame ionization detector (FID) and Thermal conductivity detector (TCD) was applied to analyze gaseous hydrocarbons and other gases $\left(\mathrm{CO}, \mathrm{H}_{2}, \mathrm{CO}_{2}, \mathrm{~N}_{2}\right.$, etc.) in the tail gas. The liquid phase was collected by a cold trap. The oil phase was separated from water phase and analyzed by an offline gas chromatography (GC2010, Shimadzu, Kyoto, Japan). Mostly the oil phase contains long chain alkanes, alkenes and small amount of alcohols. Catalyst activity was determined by CO conversion and hydrocarbons selectivity (by means of mass fraction) in all products was calculated on a carbon basis without $\mathrm{CO}_{2}$. $\mathrm{CO}$ conversion was calculated as

$$
X_{C O}=\frac{N_{C O, \text { in }}-N_{C O, \text { out }}}{N_{c o, \text { in }}} \times 100 \%
$$

where $N_{C O}$, in and $N_{C O, \text { out }}$ represent the molar flow rates of $\mathrm{CO}$ at the inlet and outlet of the reactor. Hydrocarbon selectivity $\left(S_{\mathrm{CnHm}}\right)$ was calculated on a carbon basis without $\mathrm{CO}_{2}$ :

$$
S_{C_{n} H_{m}}=\frac{M_{C_{n} H_{m}}}{\sum_{1}^{n} M_{C_{n} H_{m}}} \times 100 \%
$$

where $M_{\mathrm{CnHm}}$ represent the weight of specific hydrocarbons with the carbon number $\mathrm{n}$ in the products. To ensure the validity of data, carbon balance should be better than $95 \%$.

\section{Conclusions}

In conclusion, we have synthesized the N-doped FTO catalysts using ammonium iron citrate as precursor. XRD, XPS and Raman tests showed that the nitrogen atoms do not diffuse into carbon support but the iron lattice in order to form iron nitrides during catalyst calcination. The interaction between $\mathrm{N}$ and Fe was proven to exist from another perspective by the peak shift in XPS Fe2p spectra. The synergistic effect of $\mathrm{N}$-doped active phases and the $\mathrm{KMnO}_{4}$ pretreated carbon support was discussed by comparing their catalytic properties and performances with the undoped catalyst and untreated catalyst. A higher light olefins selectivity (44.7\%) than Fe-AC, FeN-AC and Fe-10MnK-AC catalysts were achieved over FeN-10MnK-AC catalyst. FTO performances of Fe-AC and FeN-AC justifies that nitrogen doping alone does not improve the $\mathrm{O} / \mathrm{P}$ ratio and $\mathrm{C}_{2}-\mathrm{C}_{4}$ olefins selectivity. The combined effect of inhibiting the second hydrogenation of alkenes probably associated with the competitive adsorption of hydrogen and electron donation effect of nitrogen. A comprehensive understanding of the effect on FTO catalyst performances of iron nitride needs to be further investigated.

Author Contributions: Z.T. and C.W. performed the experiments. Z.T., C.W. L.M. proposed and designed the experiments and corresponding characterizations. Y.X., W.L., L.C. and X.Z. contributed to analysis and discuss the experiment data. Z.T. and Z.S. contributed to write and polish this manuscript.

Funding: This work was supported by NSFC (National Natural Science Foundation of China Project (51476175 and 51776206) and CAS Pioneer Hundred Talents Program.

Conflicts of Interest: The authors declare no conflict of interest. 


\section{References}

1. Torres Galvis, H.M.; de Jong, K.P. Catalysts for Production of Lower Olefins from Synthesis Gas: A Review. ACS Catal. 2013, 3, 2130-2149. [CrossRef]

2. Quann, R.J.; Green, L.A.; Tabak, S.A.; Krambeck, F.J. Chemistry of olefin oligomerization over ZSM-5 catalyst. Ind. Eng. Chem. Res. 1988, 27, 565-570. [CrossRef]

3. Zhang, Q.; Wang, T.; Weng, Y.; Zhang, H.; Vitidsant, T.; Li, Y.; Zhang, Q.; Xiao, R.; Wang, C.; Ma, L. Direct conversion of simulated propene-rich bio-syngas to liquid iso-hydrocarbons via FT-oligomerization integrated catalytic process. Energy Convers. Manag. 2018, 171, 211-221. [CrossRef]

4. Davis, B.H. Fischer- Tropsch synthesis: Comparison of performances of iron and cobalt catalysts. Ind. Eng. Chem. Res. 2007, 46, 8938-8945. [CrossRef]

5. Chernavskii, P.A.; Kazak, V.O.; Pankina, G.V.; Perfiliev, Y.D.; Li, T.; Virginie, M.; Khodakov, A.Y. Influence of copper and potassium on the structure and carbidisation of supported iron catalysts for Fischer-Tropsch synthesis. Catal. Sci. Technol. 2017, 7, 2325-2334. [CrossRef]

6. Xie, J.; Torres Galvis, H.M.; Koeken, A.C.; Kirilin, A.; Dugulan, A.I.; Ruitenbeek, M.; de Jong, K.P. Size and Promoter Effects on Stability of Carbon-Nanofiber-Supported Iron-Based Fischer-Tropsch Catalysts. ACS Catal. 2016, 6, 4017-4024. [CrossRef] [PubMed]

7. De Smit, E.; Cinquini, F.; Beale, A.M.; Safonova, O.V.; van Beek, W.; Sautet, P.; Weckhuysen, B.M. Stability and reactivity of $\epsilon-\chi-\theta$ iron carbide catalyst phases in fischer- tropsch synthesis: Controlling $\mu \mathrm{c}$. J. Am. Chem. Soc. 2010, 132, 14928-14941. [CrossRef]

8. Dictor, R.A.; Bell, A.T. Fischer-Tropsch synthesis over reduced and unreduced iron oxide catalysts. J. Catal. 1986, 97, 121-136. [CrossRef]

9. Niemantsverdriet, J.; Van der Kraan, A.; Van Dijk, W.; Van der Baan, H. Behavior of metallic iron catalysts during Fischer-Tropsch synthesis studied with Mössbauer spectroscopy, x-ray diffraction, carbon content determination, and reaction kinetic measurements. J. Phys. Chem. 1980, 84, 3363-3370. [CrossRef]

10. Zhang, Q.; Kang, J.; Wang, Y. Development of novel catalysts for Fischer-Tropsch synthesis: tuning the product selectivity. ChemCatChem 2010, 2, 1030-1058. [CrossRef]

11. Cheng, Y.; Lin, J.; Wu, T.; Wang, H.; Xie, S.; Pei, Y.; Yan, S.; Qiao, M.; Zong, B. Mg and K dual-decorated Fe-on-reduced graphene oxide for selective catalyzing $\mathrm{CO}$ hydrogenation to light olefins with mitigated $\mathrm{CO}_{2}$ emission and enhanced activity. Appl. Catal. B Environ. 2017, 204, 475-485. [CrossRef]

12. Huo, C.-F.; Li, Y.-W.; Wang, J.; Jiao, H. Insight into $\mathrm{CH} 4$ formation in iron-catalyzed Fischer- Tropsch synthesis. J. Am. Chem. Soc. 2009, 131, 14713-14721. [CrossRef] [PubMed]

13. De Smit, E.; Weckhuysen, B.M. The renaissance of iron-based Fischer-Tropsch synthesis: on the multifaceted catalyst deactivation behaviour. Chem. Soc. Rev. 2008, 37, 2758-2781. [CrossRef]

14. Bartholomew, C.H. Mechanisms of catalyst deactivation. Appl. Catal. A Gen. 2001, 212, 17-60. [CrossRef]

15. Tian, Z.; Wang, C.; Si, Z.; Ma, L.; Chen, L.; Liu, Q.; Zhang, Q.; Huang, H. Fischer-Tropsch synthesis to light olefins over iron-based catalysts supported on $\mathrm{KMnO} 4$ modified activated carbon by a facile method. Appl. Catal. A Gen. 2017, 541, 50-59. [CrossRef]

16. Park, H.; Youn, D.H.; Kim, J.Y.; Kim, W.Y.; Choi, Y.H.; Lee, Y.H.; Choi, S.H.; Lee, J.S. Selective Formation of Hägg Iron Carbide with g-C3N4 as a Sacrificial Support for Highly Active Fischer-Tropsch Synthesis. ChemCatChem 2015, 7, 3488-3494. [CrossRef]

17. Gu, B.; He, S.; Zhou, W.; Kang, J.; Cheng, K.; Zhang, Q.; Wang, Y. Polyaniline-supported iron catalyst for selective synthesis of lower olefins from syngas. J. Energy Chem. 2017, 26, 608-615. [CrossRef]

18. Chen, X.; Deng, D.; Pan, X.; Hu, Y.; Bao, X. N-doped graphene as an electron donor of iron catalysts for CO hydrogenation to light olefins. Chem. Commun. 2015, 51, 217-220. [CrossRef]

19. Schulte, H.J.; Graf, B.; Xia, W.; Muhler, M. Nitrogen- and Oxygen-Functionalized Multiwalled Carbon Nanotubes Used as Support in Iron-Catalyzed, High-Temperature Fischer-Tropsch Synthesis. ChemCatChem 2012, 4, 350-355. [CrossRef]

20. Xiong, H.; Moyo, M.; Motchelaho, M.A.; Tetana, Z.N.; Dube, S.M.; Jewell, L.L.; Coville, N.J. Fischer-Tropsch synthesis: iron catalysts supported on $\mathrm{N}$-doped carbon spheres prepared by chemical vapor deposition and hydrothermal approaches. J. Catal. 2014, 311, 80-87. [CrossRef]

21. Yang, Z.; Guo, S.; Pan, X.; Wang, J.; Bao, X. FeN nanoparticles confined in carbon nanotubes for CO hydrogenation. Energy Environ. Sci. 2011, 4, 4500. [CrossRef] 
22. Anderson, R.B.; Shultz, J.; Seligman, B.; Hall, W.K.; Storch, H. Studies of the Fischer-Tropsch Synthesis. VII. Nitrides of Iron as Catalysts1. J. Am. Chem. Soc. 1950, 72, 3502-3508. [CrossRef]

23. Yang, Z.; Pan, X.; Wang, J.; Bao, X. FeN particles confined inside CNT for light olefin synthesis from syngas: Effects of Mn and K additives. Catal. Today 2012, 186, 121-127. [CrossRef]

24. Li, N.; Wang, Z.; Zhao, K.; Shi, Z.; Gu, Z.; Xu, S. Large scale synthesis of N-doped multi-layered graphene sheets by simple arc-discharge method. Carbon 2010, 48, 255-259. [CrossRef]

25. Ismagilov, Z.R.; Shalagina, A.E.; Podyacheva, O.Y.; Ischenko, A.V.; Kibis, L.S.; Boronin, A.I.; Chesalov, Y.A.; Kochubey, D.I.; Romanenko, A.I.; Anikeeva, O.B. Structure and electrical conductivity of nitrogen-doped carbon nanofibers. Carbon 2009, 47, 1922-1929. [CrossRef]

26. Dorjgotov, A.; Ok, J.; Jeon, Y.; Yoon, S.-H.; Shul, Y.G. Activity and active sites of nitrogen-doped carbon nanotubes for oxygen reduction reaction. J. Appl. Electrochem. 2013, 43, 387-397. [CrossRef]

27. Prieto, P.; Marco, J.; Sanz, J. Synthesis and characterization of iron nitrides. An XRD, Mössbauer, RBS and XPS characterization. Surf. Interface Anal. 2008, 40, 781-785. [CrossRef]

28. Al-Sayari, S.A. Catalytic conversion of syngas to olefins over Mn-Fe catalysts. Ceram. Int. 2014, 40, 723-728. [CrossRef]

29. Miller, D.G.; Moskovits, M. A study of the effects of potassium addition to supported iron catalysts in the Fischer-Tropsch reaction. J. Phys. Chem. 1988, 92, 6081-6085. [CrossRef]

30. Yeh, E.; Schwartz, L.; Butt, J. Silica-supported iron nitride in Fischer-Tropsch reactions: II. Comparison of the promotion effects of potassium and nitrogen on activity and selectivity. J. Catal. 1985, 91, 241-253. [CrossRef]

31. Torres Galvis, H.M.; Bitter, J.H.; Davidian, T.; Ruitenbeek, M.; Dugulan, A.I.; de Jong, K.P. Iron particle size effects for direct production of lower olefins from synthesis gas. J. Am. Chem. Soc. 2012, 134, 16207-16215. [CrossRef] [PubMed]

32. Galvis, H.M.T.; Bitter, J.H.; Khare, C.B.; Ruitenbeek, M.; Dugulan, A.I.; de Jong, K.P. Supported iron nanoparticles as catalysts for sustainable production of lower olefins. Science 2012, 335, 835-838. [CrossRef] [PubMed]

33. Galvis, H.M.T.; Koeken, A.C.; Bitter, J.H.; Davidian, T.; Ruitenbeek, M.; Dugulan, A.I.; de Jong, K.P. Effects of sodium and sulfur on catalytic performance of supported iron catalysts for the Fischer-Tropsch synthesis of lower olefins. J. Catal. 2013, 303, 22-30. [CrossRef] 